\title{
Práctica del skate, ciudadanía y participación política en jóvenes platenses*
}

\author{
Jorge Ricardo Saraví
}

\section{Resumen}

La ciudad de La Plata se ha caracterizado en los últimos años por ser un lugar de manifestación y expresión de luchas vinculadas a la práctica del skate. En ese marco, se han puesto en debate temas centrales como la ciudadanía, los derechos de los ciudadanos, el uso de los espacios públicos y el cuidado del patrimonio urbano. Nuestra investigación (Saraví, 2012), tuvo por objetivo fue analizar la práctica del skate llevada adelante por jóvenes en la ciudad, utilizando métodos cualitativos y de corte interpretativo. A través de los relatos de los protagonistas y con la ayuda de documentos escritos, hemos tratado de construir un relato interpretativo de cómo diferentes hechos y sucesos fueron modificando no solamente los escenarios de la práctica del skate en la ciudad, sino también la vida urbana de La Plata. Hechos que fueron constituyéndose en jalones en la búsqueda de afirmación de la ciudadanía de los jóvenes skaters platenses.

\section{Palabras clave}

Skate - jóvenes - ciudadanía.

* Artículo recibido el 18 de Mayo de 2015. Aceptado el 6 de Julio de 2015.

** Jorge Ricardo Saraví integra el Área de Estudios e Investigaciones en Educación Física (AEIEF). Instituto de Investigaciones en Humanidades y Ciencias Sociales (IdIHCS) UNLP-CONICET. Facultad de Humanidades y Ciencias de la Educación. Universidad Nacional de La Plata.

Correo electrónico: jrsaravi@gmail.com 


\section{Abstract}

The city of La Plata has been characterized in recent years for being a place of manifestation and expression of struggles linked to the practice of skateboarding. In this framework, discussions have been central themes such as citizenship, the rights of citizens, the use of public spaces and urban heritage care, among other issues of interest. The starting point is the research for our own Master Thesis (Saraví, 2012), aimed at analyzing the practice of skateboarding carried out by young people in the city. To this end, we used qualitative research methods and interpretative cut (particularly field observations and semi-structured interviews). In this article, through the stories of the protagonists and with the help of some written documents, we have tried to build an interpretive account of how different facts and events were changing not only the stages of the practice of skateboarding in the city but also urban life of La Plata. Facts that were becoming milestones in the search for affirmation of youth citizenship platenses skaters.

\section{Keywords}

Skate, youths, citizenship

\section{A modo de introducción: skate y espacio público}

Los primeros estudios sobre el skate se localizan en la década de 1990. En el hemisferio Norte podemos mencionar la tesis doctoral de Pegard (1996) en Canadá, y los estudios de Calogirou y Touché (1995) en Francia, quienes fueron quizás los primeros en estudiar al skateboarding desde la perspectiva de las ciencias sociales. Pero también por esos mismos años comenzaban las primeras investigaciones en América Latina: Uvinha (1997) fue el pionero, al estudiar las prácticas skaters en los alrededores de San Pablo. Más recientemente, Honorato (2005) se propuso indagar en las relaciones entre la práctica cultural del skate y el poder en la escuela. Graeff Bastos (2006) buscó en su tesis de maestría problematizar el universo social del skate profesional. Por ese mismo momento, Brandão (2006) desarrolla en sus estudios una historia cultural del skateboarding en Brasil. En países latinoamericanos de habla hispana se registra el estudio de Failache y Olivera en Montevideo (2002), y el de Cornejo Améstica y su grupo de colaboradores en Concepción, Chile, quienes llevaron adelante un trabajo investigativo con niños y adolescentes skaters (Cornejo Améstica et al., 2006).

En el caso de la ciudad de La Plata, la práctica del skate ha tenido diferentes implicancias, entre ellas, disputas por la búsqueda de lugares y espacios, las cuales 
llevan ya más de una década. Algunos autores sostienen que la práctica skater implica una apropiación, transformación y reutilización de los espacios urbanos (Calogirou y Touché, 2000, Almada Flores, 2010). A continuación haremos mención sintéticamente de algunas nociones que nos permitan entender las diferentes lógicas en relación con el uso de los espacios públicos en esta práctica en particular (Saraví, Chaves y Machemehl, 2012). En una investigación antropológica referida a las experiencias urbanas en la ciudad de La Plata, Segura (2010), parte de la noción de Michel De Certeau (1996) acerca del espacio público en tanto lugar practicado. El autor sostiene que no hay que tomar al espacio público como el lugar de todos, en una imagen idílica o idealizada, dado que en su producción intervienen desigualdades, exclusiones y conflictos, al igual que en todas las dimensiones de la vida social. Se destaca entonces la necesidad de poder analizar esas tensiones y sus resoluciones en los espacios desde una mirada política de lo urbano. Para profundizar esta perspectiva es pertinente la definición de Fernando Carrión (2007)

...la ciudad en su conjunto es un espacio público a partir del cual se organiza la vida colectiva y donde hay una representación de esa sociedad. De allí surge la necesidad de entenderlo como uno de los derechos fundamentales de la ciudadanía: el derecho al espacio público, porque permite reconstruir el derecho a la asociación, a la identidad y a la polis (2007: 83).

En nuestro caso, y considerando que el problema a investigar eran las prácticas de los sujetos, los discursos y su vinculación con dichas prácticas, la elección de la metodología estuvo centrada en utilizar métodos de investigación cualitativa y de corte interpretativo. Para ello, se realizaron entrevistas y observaciones. También hemos utilizado otras fuentes de información que consideramos de carácter más bien complementario, tales como el análisis de expedientes y notas oficiales. Fueron entrevistados en total siete skaters, cinco varones y dos mujeres. Asimismo entrevistamos a los interlocutores de los jóvenes, algunos de ellos en el ejercicio de cargos de gestión u ocupando puestos de organización; fueron entrevistados seis sujetos, cinco hombres y una mujer. En total, fueron realizadas trece entrevistas en profundidad.

\section{Skaters en pos de un espacio propio}

Si bien muchas ciudades del mundo y, en particular de Latinoamérica, cuentan con skateparks propios desde hace muchos años, este no era el caso de La Plata hasta hace relativamente poco tiempo. ${ }^{1}$ Al momento de la realización del trabajo de campo de

\footnotetext{
${ }^{1}$ Un skatepark es un sitio preparado especial y artificialmente para esta práctica. También suelen ser denominados "pistas de skate".
} 
esta investigación no existía ninguna pista de skate en la ciudad, e incluso algunas iniciativas de construcción habían sido rechazadas, cambiadas de lugar o dilatadas en el tiempo. ${ }^{2}$ El primer skatepark público y de acceso gratuito de la región fue inaugurado en la ciudad de Ensenada en junio del año 2009. ${ }^{3}$ La aparición de espacios públicos deportivos adaptados especialmente a la práctica del skate en la ciudad de La Plata es reciente, dado que los tres existentes actualmente se inauguraron en el transcurso del año 2011. Partiendo de una situación donde no existía ninguno, en solo un año, la ciudad pasó a tener tres. ¿Cómo se dio todo este proceso de manera tan vertiginosa? Esta rapidez fue solo aparente, porque, como veremos a continuación, en realidad habían pasado diez años desde que se había efectuado por primera vez una propuesta formal e institucional para la implementación de una pista de skate en La Plata.

En la búsqueda documental realizada para nuestra investigación, localizamos un proyecto de Ordenanza municipal de agosto de 2001, en el cual -bajo la firma de un concejal de la Unión Cívica Radical- ${ }^{4}$, se proponía "la construcción de rampas o skateparks para la práctica deportiva denominada skateboarding en las plazas Moreno, Belgrano, Malvinas Argentinas, Paso, Saavedra, San Martín y/o en otras u otros, incluyendo espacios públicos situados en la periferia" (Expediente HCD 35309, 31/08/2001). El objetivo de dicha iniciativa era claro en sus considerandos: se proponía crear un espacio "adecuado, seguro y propio" para posibilitar la práctica skater con "acceso masivo y gratuito". Pero, al mismo tiempo, con la intención de que no se practicara más en "bancos o monumentos existentes en las distintas plazas de la ciudad" y con el objetivo de evitar que los skaters se transformaran en "un peligro para aquellos que se encuentran en las plazas o parques pretendiendo un momento de tranquilo esparcimiento". La propuesta tenía en su presentación una doble faceta que parece haber acompañado también a los posteriores proyectos de creación de espacios para el skate: brindarles a los jóvenes un espacio propio para esa práctica, pero, a la vez, alejarlos de los lugares públicos donde estaban perturbando y generando conflictos o situaciones de peligro para otros ciudadanos. Extrañamente, una iniciativa que estaba francamente a favor de la práctica del skate, hacía referencia a los skaters pero dando a entender a la vez que no los incluía dentro del grupo de vecinos que podía pretender "un momento de tranquilo esparcimiento". El texto presentado dejaba en claro que -a esa fecha- "la ciudad de La Plata no cuenta con ningún skatepark", y que dichos espacios permitirían "atraer a niños y jóvenes hacia la práctica de deportes

\footnotetext{
2 Hacemos referencia a la investigación que condujo a la presentación de "Skate, espacios urbanos y jóvenes en la ciudad de La Plata", Tesis de Maestría en Educación Corporal UNLP (Saraví, 2012).

${ }^{3}$ La ciudad de Ensenada se localiza a $10 \mathrm{~km}$ de La Plata y de acuerdo con los datos del censo de 2010, tiene 55.000 habitantes. El partido de La Plata, que tiene 650.000 habitantes, en el año 2010 aún no contaba con una pista de skate propia.

${ }^{4}$ La U.C.R. o Unión Cívica Radical era en ese momento la oposición. El año mencionado corresponde a la intendencia de Julio César Alak, del Partido Justicialista (P.J.). Alak condujo la ciudad en sucesivas reelecciones entre diciembre de 1991 y diciembre de 2007.
} 
relativamente nuevos". El documento solicitaba la asignación de un monto para su construcción dentro de la partida presupuestaria municipal. El Concejo Deliberante luego le solicita mediante otra nota a la Dirección de Planeamiento Urbano (órgano del poder ejecutivo municipal) que se expida sobre la cuestión. Centrándose en el "riesgo para los usuarios", el ejecutivo finalmente desestima la iniciativa presentada en mayo de 2002, y el expediente pasa de esta manera al Archivo del Concejo Deliberante en marzo de 2005 (Expediente HCD 35309, marzo de 2005). Se podría inferir que quizás en la negativa hayan podido existir también otras causas políticas y/o económicas, como por ejemplo, la posibilidad de que haya sido rechazado por haber sido presentado por un partido político opositor. Lo que sí está claro es que, hasta ocho años después, no volvería a aparecer ninguna propuesta o iniciativa concreta desde un marco institucional estatal para construir un skatepark en la ciudad. Pero la nota era en sí misma un hito: el skate platense comenzaba de esta manera a "pedir pista" en un sentido real y metafórico.

Unos años después, en febrero de 2008, un grupo de jóvenes skaters presentan -con el apoyo del presidente de la "Asociación Civil Utopías de un Barrio", del barrio Altos de San Lorenzo-, una nota al Concejo Deliberante donde le solicitan a la municipalidad "que acompañe nuestro proyecto incorporando al mismo como de interés deportivo, le adjuntamos ideas y lugares posibles para desarrollar la actividad del deporte skate" (Expediente número 46287, HCD, 18/2/2008). La nota presentada iba acompañada de 310 firmas, donde, en una mirada detallada, encontramos el nombre y apellido de muchos jóvenes conocidos en el ambiente skater, lo cual testimoniaba el sustento que tenía la iniciativa en ese momento. Lo que caracterizaba con más fuerza a esa nota era la intención de los jóvenes de hacerse oír. Justamente mencionan en el texto que el foro de seguridad "se comprometió con nosotros a arbitrar los medios necesarios para que, por lo menos nuestras ideas sean escuchadas y quizá tener este espacio en la ciudad de La Plata" (la cursiva es nuestra). Luego, la nota fue girada desde el Concejo hacia el poder ejecutivo para "requerir información acerca de predios municipales en los cuales se puede practicar dicho deporte" (Expediente 46287, HCD, folio 13, mayo 2008). A la fecha de escritura de la tesis antes mencionada, (Saraví, 2012), el expediente se encontraba aún en la Comisión de Planeamiento del Concejo a la espera de una resolución definitiva. La propia gestión municipal que unos años más tarde implementaría la construcción de tres skateparks, no daba respuesta clara a esta nota fruto de una inquietud del grupo de vecinos.

Por esa misma época, el diario local de mayor tirada, El Día, destaca en un artículo la existencia de dicha nota presentada en la municipalidad. ${ }^{5}$ Bajo el título "Crece la

5 También localizamos otras notas anteriores en el mismo diario El Día, aparecidas en el año 1999 y 2000, referidas a skaters que habían sido detenidos en el Teatro Argentino de la ciudad de La Plata, pero estas estaban más centradas en la cuestión judicial y no en la práctica misma del skate (varias de ellas correspondían a la sección "policiales"). 
movida "skaters" y reclama un espacio propio", el periodista Francisco Lagomarsino mencionaba que "Hoy buscan un atajo que los lleve de su "spot" urbano clásico -la Torre I de plaza Moreno- al espacio propio. Por eso recogen firmas desde hace varias semanas, y merced a ese impulso ya lograron llamar la atención de la Comuna" (El Día, 25/5/2008). Efectivamente, el periodista estaba en lo cierto: no solo habían logrado llamar la atención de la municipalidad -que de ahí en más ya no podría ignorarlos-, sino que ya estaban haciéndose ver y oír por el resto de las instituciones y ciudadanos de La Plata. Indudablemente, el recorrido iniciado con la nota presentada colectivamente al Concejo había comenzado a surtir efecto. Esta iniciativa de presentar una nota colectiva fue la primera acción intencional con el objetivo de constituir una asociación o agrupación de skaters -es decir, transformarse en un colectivo con una cierta institucionalidad-, hecho que quizás podría haber sido significativo pero que luego no llegó a plasmarse.

\section{El proyecto de skatepark en Plaza Belgrano}

El spot para la práctica del skate en la ciudad de La Plata que ha acumulado más instancias de diálogos, negociaciones y conflictos por el uso de los espacios públicos ha sido sin dudas el Teatro Argentino. ${ }^{6}$ En los últimos años habían surgido situaciones conflictivas entre dos actores sociales: por un lado los vecinos del teatro, y por el otro los jóvenes que allí practicaban skate. El apogeo de los conflictos y disputas se dio en particular entre los años 2008 y 2010. En torno a ese lugar se suscitaron también la mayor cantidad de diálogos, negociaciones y alternancias diferentes: aquí se estableció una relación directa y estrecha con los responsables del teatro con el objetivo de delimitar las áreas donde los skaters podían practicar y cómo practicar, compatibilizando intereses y necesidades.

En ese contexto de conflictos empieza a pensarse en iniciativas concretas de crear una pista propia para la práctica. La primera opción que apareció, y que parecía bastante sólida, fue construir un skatepark en Plaza Belgrano (plaza pública de ubicación céntrica en la ciudad). Dicho proyecto llegó a la etapa de diseño y contó con la participación activa de varios skaters platenses. Unos de ellos sostenía al respecto que "nos llevó un montón de trabajo" (Juan, entrevista personal, 29 de diciembre de 2009). ${ }^{7}$ Por esa misma época algunos de los jóvenes habían armado una carpeta con el objetivo de presentarla en ámbitos de toma de decisión política. Contenía una elaborada y cuidada

\footnotetext{
$6 \quad$ Spot es un anglicismo utilizado tanto en idioma español como en otras lenguas latinas, para designar un lugar de características muy propicias para la práctica del skate (se utiliza asimismo en otras prácticas como el surf y el windsurf).

${ }^{7} \mathrm{El}$ lector observará que en las citas de las entrevistas no figuran los apellidos de los entrevistados; asimismo los nombres de pila colocados son ficticios. Todo ello con miras a preservar la privacidad de quienes participaron en la investigación, tal como fuera acordado con ellos al momento de realizar la entrevista. En otros casos (entrevistas a adultos) hemos colocado solo el cargo que el entrevistado desempeñaba al momento de ser entrevistado.
} 
presentación donde constaba una fundamentación de los beneficios físicos, psicológicos y sociales de la práctica, había sido elaborada por Juan junto a otros miembros del grupo e incluía información acerca de skateparks y datos estadísticos que ellos habían obtenido a través de Internet y en otros sitios. La carpeta fue entregada a varios funcionarios municipales, entre otros, al Director de Juventud y el Director de Deportes, y, si bien recibió elogios de parte de varios de esos receptores, aparentemente no habría sido tenida en cuenta, al menos no de manera explícita.

Este proceso que podríamos indicar como el verdadero inicio de acciones por la construcción de un skatepark público empezó a verse reflejado en el diario El Día. El matutino local le dedicó tres notas: la primera "Avances para crear parque de skaters en 13 y 40" (14/2/2009), otra que apareció bajo el título "Construirán una pista de skaters en Plaza Belgrano" (17/6/2009) y otra más, titulada "Skaters platenses piden pista en Plaza Belgrano" (28/6/2009). En dichos artículos se daban algunas precisiones técnicas de la pista, lo cual demostraba en parte el grado de avance y de factibilidad del proyecto en ese momento. Pero el lugar elegido presentaría algunas dificultades: aparentemente fue desestimado porque, en palabras del Director de Juventud de la municipalidad,

"hubo una movida vecinal en contra del proyecto, además de que el lugar no era el adecuado, porque si nosotros queríamos darle la envergadura que queremos darle al skatepark, cortás a la mitad la plaza y la gente no puede pasar de un lado para el otro. Lo cual en vez de generar un beneficio, generás una molestia en los vecinos que utilizan el espacio público" (Entrevista personal, 23 de marzo de 2010).

Al respecto, desde la perspectiva de una chica skater entrevistada, aparecía como significativo el tema de las quejas vecinales y un solapado conflicto generacional:

"No sé bien por qué fue [que no se hizo], me parece ser que la municipalidad remodeló toda la plaza Belgrano, que la arregló toda, entonces a partir de eso creo que lo cambiaron de lugar, además los vecinos se quejaron que iba haber un lugar, son gente grande y bastante quejosa" (Marina, entrevista personal, 15 de enero de 2010).

El skatepark en Plaza Belgrano finalmente no llegó a concretarse y no pasó del nivel de planificación. A pesar de la resistencia de los vecinos, un poco más tarde los skaters volverían a presentar la iniciativa de concretar el skatepark en esa misma plaza.

\section{Conflictos por el uso de los espacios públicos: el Teatro Argentino}

Mientras los tiempos administrativos municipales corrían en relación con el proyecto de la pista en plaza Belgrano, los skaters seguían practicando activamente, en particular 
en el Teatro Argentino, uno de sus sitios preferidos. ${ }^{8}$ Una de las cuestiones más relevantes que se manifestaban en las observaciones realizadas en el marco de la investigación fue el componente sonoro que tiene el skate: el frotar de las ruedas, la fricción que se produce entre las superficies y el desplazamiento de la tabla. Este aspecto, ya mencionado y descripto por Claire Calogirou y Marc Touché en su investigación en Francia al caracterizar al skate como una práctica "altamente visible y sonora" (Calogirou y Touché, 2000: 33), fue justamente una de las cuestiones en el origen de 'fricciones' con los vecinos platenses. Varios habitantes de uno de los inmuebles cercanos presentaron una nota dirigida al Director General del Teatro Argentino en la cual querían formular una denuncia que involucraba la actividad skater que desarrollaba un grupo de adolescentes. La cuestión de los ruidos molestos fue uno de los puntos de anclaje de los argumentos de los vecinos, quienes pedían en el mencionado escrito a la máxima autoridad del teatro que "implemente los medios correspondientes para que desalojen el lugar". La nota finalizaba haciendo referencia a "los daños al patrimonio cultural y al espacio público por la práctica de una actividad realizada fuera de contexto" (Nota Teatro Argentino No 173, marzo de 2009). Esa era la forma que encontraban estos vecinos para llevar adelante lo que podría llamarse el 'manual del ciudadano correcto'. Según Otaviani, el espacio público es un espacio sentido e interpretado como propiedad de todos, pero justamente "Este punto puede ser generador de conflictos sociales entre diversos grupos u actores sociales. En esta instancia, entra en juego la multiperspectividad de los actores sociales frente a una misma realidad" (Otaviani, 2009: 183). Que todos se sientan dueños del espacio público incluye, quizás, la posibilidad de que algunos de esos todos se sientan con más derechos a proteger esa propiedad colectiva, o que sean unos pocos quienes intenten definir cómo debe protegerse ese patrimonio. Se evidencia así una dicotomía en la construcción del nosotros (los vecinos) y los otros (los skaters).

Mientras desde los ámbitos municipales elaboraban esa nota de reclamo, el responsable del teatro ya les había respondido en forma directa a los vecinos -en una extensa carta-, afirmando que, desde que había asumido su cargo, él había notado la presencia de estos "jóvenes vecinos" (como él los denomina, cursiva en el original) "que se citaban [...] para practicar una actividad singular, pero no por ello delictiva, conocida como skateboard" (Nota 256 Teatro Argentino, 6/4/2009). Allí hace también referencia a la preservación edilicia, reconociendo que "dicha práctica comenzó a provocar un sensible deterioro a las instalaciones del Teatro". Allí explicita también el alcance preciso del acuerdo logrado con los chicos: acotar el uso del espacio a la esquina de las calles 9 y 53, no excediéndose de las 20 horas y con prohibición de usar "barandas, fuentes y escaleras de acceso". El director finaliza destacando el camino logrado,

\footnotetext{
${ }^{8}$ Para más detalles de los sitios de práctica en la ciudad de La Plata, remitimos al lector a la lectura del capítulo de la tesis (Saraví, 2012), titulada "Los espacios urbanos y la práctica del skate".
} 
utilizando para ello los conceptos 'entendimiento', 'compromiso mutuo', 'convivencia' y 'tolerancia plena' (sic). Su frase de cierre resume un pensamiento abierto y claro: "esta solución es la que más se condice con un Centro de las Artes, al que lo entiendo como un espacio que no excluye a nadie, en el que se pueda pensar, crear, expresar y participar respetando a todos y en absoluta libertad" (Nota 256 Teatro Argentino, 6/4/2009). Hasta la elaboración del presente artículo, los vecinos no volvieron a presentar ninguna nota de queja. Sin embargo, el mantenimiento del acuerdo en el teatro fue encontrando algunas dificultades, las cuales irían en aumento.

\section{Los diálogos, los consensos y las dificultades para sostenerlos}

El acuerdo entre el funcionario del teatro y los jóvenes, descripto en la nota mencionada, había sido fruto de los diálogos preexistentes. En ese entonces, el spot del teatro estaba en lo que quizás fue uno de los picos de mayor concurrencia skater, entre diciembre de 2008 y febrero de 2009. Además del sonido, uno de los puntos de oposición al skate suelen ser las roturas y daños que se ocasionan en los mobiliarios urbanos. La práctica del skate no se trata solamente del uso y apropiación del espacio, sino que implica la transformación del espacio (Calogirou y Touché, 2000): los skaters modifican el espacio no solo porque lo adaptan, sino porque lo desgastan. El roce permanente de las ruedas y tablas contra diferentes superficies produce un deterioro. Pero más allá del desgaste de las superficies concretas existe un imaginario muy consolidado en la sociedad acerca de que el skate rompe. El imaginario urbano de que el skate "rompe" la ciudad, ${ }^{9}$ está presente desde los años 80 con la aparición del lema "skate and destroy" (Camino, 2008), el cual parece continuar hasta el presente como una especie de eslogan de un cierto orgullo skater.

Otro de nuestros entrevistados, dentro de su enojo por los cuestionamientos de los vecinos, deja un margen de posibilidad para el reconocimiento de esos daños diciendo: "están todos locos, porque no nos quieren los del teatro viste, esos nos ven como re vándalos, que rompemos todas las cosas pero por ahí nosotros las rompemos" (Leo, entrevista personal, 15 de enero de 2010). Los skaters expresaban en ese momento que los vecinos querían hacerlos cargo de los destrozos del teatro; en respuesta a ello fueron al diario a explicar su accionar y además hablaron con el director del teatro en persona. ${ }^{10}$ El funcionario explicaba que, si bien por una parte comprendía o intentaba comprender a los skaters, también, en cierta manera, coincidía en algún punto con estas críticas hacia las roturas:

\footnotetext{
${ }^{9}$ Según Alicia Lindon "Los imaginarios (urbanos) expresan [...] supuestos que no se cuestionan, lo que se supone que existe, aquellos aspectos, fenómenos y características que se asumen por parte de los sujetos como naturales, porque han sido integrados, entrelazados, en el sentido común" (Lindon, 2007: 9).

${ }^{10}$ Ello tuvo eco en el diario El Día de La Plata, que bajo el título "Polémica por skaters en Teatro Argentino" publicó una nota referida a la cuestión el día 13 de marzo de 2009.
} 
"...la verdad es que estas no son instalaciones que estén adecuadas para esta exigencia porque es un deporte que genera algunos inconvenientes, no solamente para la gente que pueda transitar alrededor del teatro, sino para el patrimonio físico, rompen escaleras, rompieron la fuente, gran parte de las veredas se han roto por la exigencia de la actividad que ellos realizan. Lo que me doy cuenta, a medida que los veo, es que no es simplemente el andar en una patineta, van buscando nuevos desafíos y es una forma también de expresarse" (Director del Teatro Argentino, entrevista personal, 20 de marzo de 2010).

Evidentemente, la situación que se había generado era atípica: por primera vez un funcionario de alto rango se acercaba a ellos con un interés genuino de escucha y diálogo. Era un jalón importante en el camino: quizás los skaters no imaginaban que pocos años después, en 2011, el propio intendente de la ciudad estaría compartiendo con ellos la inauguración de los nuevos skateparks y efectuando declaraciones sobre la importancia del skate.

En base al diálogo sostenido y a la confianza mutua desarrollada, se habían logrado los acuerdos. Tal como nos explicaban los jóvenes, habían llegado a coordinar ciertas pautas de convivencia con el director del Teatro Argentino. Sin embargo, sostener esos acuerdos no fue tarea fácil, empezaron a surgir disidencias y desinteligencias entre los jóvenes. Uno de ellos lo manifestaba así: "fue muy difícil hacerle entender a los chicos y a los adolescentes de que no se tenía que hacer esto y esto, y como el skate en sí es un deporte rebelde, bueno, transgredimos hasta que nos echaron" (Juan, entrevista personal, 29 de diciembre de 2009). El propio funcionario público, a pesar de su voluntad conciliadora, entendía luego que "hemos tenido que dejar caer el acuerdo porque es imposible de sostener porque siguen rompiendo o andando en lugares que no corresponden, nos siguen rompiendo las fuentes" (Director del Teatro Argentino, entrevista personal, 20 de marzo de 2010). Juan cuenta con desazón una de sus últimas reuniones con el Director: "nosotros le dijimos mirá, echanos, o sea, es incontrolable, yo no puedo... Yo le dije echanos porque ya hablé con todos, me cansé... o sea, yo también ya estaba cansado" (Juan, entrevista personal, 29 de diciembre de 2009). Pese a su gran amplitud de criterios y de su fuerte voluntad conciliadora, él también entendía que su función era cuidar el teatro, en un marco donde existen otras dificultades que también coadyuvan "este edificio es muy complejo no solamente para su mantenimiento, sino para el control, por la pobreza de presupuesto, por falta de gente técnica específica y cada cosita que se rompe nos cuesta mucho" (Director del Teatro Argentino, entrevista personal, 20 de marzo de 2010). A pesar de que él consideraba que podría haber establecido con los jóvenes un acuerdo duradero y profundo que enviase un mensaje interesante a la sociedad platense, guardaba en sí la tristeza de no haber podido concretarlo. Si bien la forma en que terminó esta instancia no fue la más deseable para los protagonistas del diálogo, consideramos que fue una etapa muy fructífera donde 
los skaters, después de muchos años de práctica solitaria en veredas, rampas y bordes, lograban 'sentarse' a dialogar con otros actores sociales sobre lo que significaba el skate para ellos, expresando allí qué querían. En ese ámbito de receptividad podían expresar lo que necesitaban: que se los respetara y que se les diera un espacio propio. Esta vez, la voz asumía carácter oral, pero sin dudas establecía una línea de continuidad con la nota escrita que fuera presentada en 2008 en la municipalidad y que mencionáramos en páginas anteriores.

\section{El proyecto 115 en el presupuesto participativo}

Pese a que la municipalidad tenía detenida la iniciativa del skatepark en Plaza Belgrano, el grupo de skaters continuaba con su entusiasmo en relación con la iniciativa: sin dudas los conflictos que estaban viviendo cotidianamente en el teatro obraban como un acicate. En ese momento, los hechos comenzaban a superponerse como un mazo de naipes y, cada tanto, era necesario barajar y dar de nuevo. Los jóvenes decidieron -al no encontrar ni fondos de financiamiento, ni apoyo oficial-, presentar el proyecto de skatepark en la elección del Presupuesto Participativo, donde competiría contra otros proyectos. Los presupuestos participativos, implementados por muchos municipios de distintos rincones geográficos del mundo han tenido particular desarrollo en Latinoamérica, en especial a partir del éxito y la difusión internacional del Presupuesto Participativo de Porto Alegre, Brasil. En esa ciudad fue implementado en forma masiva entre los años 1989 y 2004 durante tres intendencias diferentes del PT (Partido de los Trabajadores). "El objetivo era permitir que cada ciudadano pudiera intervenir en la creación de políticas públicas y en las demás decisiones de gobierno que tuvieran importancia para el futuro de la ciudad" (Genro, 1998: 29). La base de los presupuestos participativos está estrechamente vinculada a la idea de democracia participativa, donde el ciudadano es un protagonista activo y no solo un emisor de votos cada cierta cantidad de años. El interés es crear nuevos centros o polos de decisión, potencializando el ejercicio de los derechos de la ciudadanía y contribuyendo a la socialización de la política (Genro, 1998). En el caso de la ciudad de La Plata, el presupuesto participativo es definido por la municipalidad en su página web como "una forma de democracia directa, el primer paso hacia la superación de la democracia representativa formal; consiste en la organización de un proceso de asambleas barriales, regionales y comunales, en las cuales la ciudadanía discute y decide cuáles son las políticas públicas que el gobierno debe ejecutar en las distintas áreas y cuál es su orden de prioridades" ${ }^{11}$ Esta política municipal está compuesta de varias acciones: el primer paso consiste en que el gobierno municipal asigna una determinada partida presupuestaria al programa del Presupuesto Participativo; en segundo término se

\footnotetext{
11 Información extraída de la página web oficial de la Municipalidad de La Plata: http://www.gestion.laplata.gov.ar/presupuesto-participativo
} 
discuten en asambleas barriales las prioridades en las políticas públicas del gobierno local para el gasto de la partida presupuestaria asignada y allí se proponen las obras concretas. El tercer paso es que los proyectos se someten a votación primero en la asamblea (para tener derecho a votar hay que asistir por lo menos dos veces), y luego, con los que salgan seleccionados, se convoca a una votación mayor donde todos los ciudadanos tienen derecho a participar, en la cual se puede votar presencialmente o por medio del envío de mensajes de texto de teléfonos celulares. Una vez computados los resultados, la municipalidad asume el compromiso de concretar las obras ganadoras.

A partir de la decisión de presentarse en el marco del Presupuesto Participativo 2010 (votado a fines de 2009), los skaters comienzan a asistir a las asambleas con su proyecto bajo el brazo. Hasta allí la idea era hacer el skatepark en Plaza Belgrano. Es así que se encuentran en el mismo sector de votación, denominado Casco 2, con otro proyecto urbano de espacio deportivo que ya estaba en marcha y toman contacto con el presidente de esa Junta Comunal (Casco 2, La Plata) y referente político barrial, ${ }^{12}$ que estaba liderando la presentación de un proyecto de "complejo deportivo infantojuvenil" para que sea aprobado en esa votación de presupuestos participativos. Había sido planificado para una antigua playa de estacionamiento de ómnibus y en las cercanías de la estación de trenes local, en las calles 40 y 115 . El encuentro de los jóvenes skaters, que pugnaban por encontrar un espacio donde desarrollar sus prácticas sin conflictos, con este grupo de vecinos, que estaban intentando plasmar su movida de complejo deportivo, es casi azarosa, pero rápidamente toman conciencia de que tienen algo en común: ambas se refieren a la creación de espacios para prácticas deportivas y de esparcimiento. Por un lado el proyecto con canchas de handball, voleibol, futbol, basquetbol y tenis, por el otro, el proyecto de pista de skate. La idea original del skatepark, que había nacido como un proyecto autónomo, sería ahora retomada en el marco de un proyecto mayor que incluía otros aspectos $y$, particularmente, otros deportes. La experiencia política del mencionado dirigente vecinal y la necesidad de los jóvenes de encontrar partenaires para su emprendimiento obraron como aceleradores para el acercamiento y la fusión. A partir de esta interacción con un nuevo interlocutor que los podía escuchar, los jóvenes terminan incluyéndose en el proyecto. "Entonces, cuando yo presenté el proyecto, ellos dijeron, 'no, bueno, nosotros levantamos el proyecto y nos unimos al proyecto este porque nos parece superador', entonces ahí empezamos a charlar todo" (Presidente de la Junta Comunal, entrevista personal, 13 de abril de 2010). Si bien en un principio su interés en convocar

\footnotetext{
12 Las Juntas Comunales son órganos colegiados participativos integrados por entidades de bien público, colectividades y cooperativas, uniones vecinales y otros tipos de organizaciones sociales, que tienen "por función estimular la acción comunitaria y la participación ciudadana en la gestión municipal. En la actualidad las juntas son 18 (16 funcionan en la periferia y 2 se encuentran en el casco urbano de la ciudad)" (Pagani, 2008: 81).
} 
a los jóvenes skaters fuese, presumiblemente, para concentrar votos para su proyecto, luego se fue relacionando poco a poco con ellos y finalmente la inclusión del proyecto pista de skate se constituyó en una convicción sincera. Así como la llegada de los skaters a la reunión tuvo un efecto sorpresa en ese ámbito, quizás podríamos pensar que lo tenía también para la comunidad platense: salvo la nota de 2008 al Concejo Deliberante, era la primera vez que la presencia de los jóvenes se corporizaba en acto en una situación por fuera de la práctica misma en el teatro y en la Torre. ${ }^{13}$ Los skaters dejaban así momentáneamente sus tablas para incursionar en las arenas de lo político. Esta acción permitió que se abriera, por primera vez, al debate público la cuestión de si para la ciudad era importante o no la construcción de un predio que incluyera un skatepark. De ahí en más, la voz de los chicos platenses que hacían skate ya no podría dejar de ser escuchada.

\section{Los skaters en las asambleas y en campaña por los votos}

A partir de ese momento, se abría para estos jóvenes skaters una nueva instancia de participación al comenzar a asistir -de manera activa- a las asambleas del presupuesto participativo. Otro entrevistado menciona al respecto "fui a las asambleas también... llevamos mucha gente en la primera reunión y mucha gente en la última [...] después nos dijeron que tendríamos que haber traído mucha gente a todas las asambleas para poder votar y no pudimos en ese momento" (Pedro, entrevista personal, 15 de enero de 2010). Una entrevistada nos comenta cómo se acercó a esos espacios participativos:

"Yo me enteré que Juan estaba llevando el proyecto hace cuatro años y que lo habían metido en el presupuesto participativo este año, entonces fui a las asambleas, más que nada a las últimas y ahí fue cuando me empecé a meter más todavía, que me empezaron a pedir que se controlara la mesa de votación y esas cosas y yo me metí porque me interesó, porque tenía ganas de que salga adelante el proyecto" (Marina, entrevista personal, 15 de enero de 2010).

El 115, tal como se lo denominó, era un proyecto que estaba aún en borrador. ${ }^{14} \mathrm{La}$ única precisión con que se contaba era de cuántos subespacios deportivos se compondría. Con esa idea y con ese impulso, postularon contra los otros proyectos que se presentaban en el marco de la votación del presupuesto participativo.

\footnotetext{
13 Hacemos referencia a la Torre Administrativa 1, sita en 12 esquina 50. Es un edificio público donde funcionan, entre otras, dependencias de la Municipalidad de La Plata y de la Dirección General de Cultura y Educación de la Provincia de Buenos Aires. Era muy utilizada en sus veredas y adyacencias por los jóvenes skaters.

${ }^{14}$ Todos los proyectos que se presentaban en el Presupuesto Participativo para ser votados estaban numerados, a los que correspondían al Casco 2 se les había asignado del número 113 al 119. Quizás por fruto del azar, al proyecto de campo deportivo y skatepark -que iba a estar justamente ubicado en la calle 115-, se le asignó también el número 115.
} 
Un grupo de jóvenes fue el más activo, realizando acciones dentro de la campaña a favor de que el proyecto de skatepark pudiera ganar en la votación de presupuestos participativos. Durante el proceso fueron varias las maneras que se utilizaron para llegar a los potenciales votantes. En Internet multiplicaron la convocatoria de manera virtual. En los sitios Taringa, Fotolog y en laplataskate.com, así como en diversos foros, se realizó campaña a favor del voto por el proyecto 115. Además, esta se extendió al plano de los contactos persona a persona saliendo a repartir volantes en comercios del centro de la ciudad. Los jóvenes se ubicaron también en la puerta de la escuela donde se efectuaba la votación, buscando transeúntes para que voten. Si bien hubo participación por parte de muchos skaters, no todos se interesaron en la iniciativa de concretar el proyecto de skatepark, e incluso muchos no votaron. Otros mantenían su conexión con el tema preguntando a sus compañeros qué pasaba con eso. Aquellos jóvenes que participaron activamente en llevar adelante primero el proyecto de Plaza Belgrano y luego el proyecto 115 eran descriptos de manera muy lapidaria por el funcionario municipal entrevistado: "la verdad que me costó muchísimo lograr que participaran [...], nos costó muchísimo, no solo a mí, sino a mi grupo de trabajo, llamarlos cuatrocientas veces, buscarlos por todos lados, lograr que vinieran a las reuniones, lograr que fueran responsables" (Director de Juventud, entrevista personal, 23 de marzo de 2010). Ellos a su vez tenían una actitud crítica y de desconfianza hacia algunos de esos políticos. Los skaters tenían otro punto de vista, y describían al funcionario como alguien que

"...tiene bastante poder, es un político muy fiaca, los políticos son muy fiacas, muy vagos, o sea no lo conozco personalmente como para decirte, pero tuvimos muchas peleas fuertes. Nosotros no somos boludos, sabés que el día de mañana cuando $X$ diga este skatepark lo empecé yo, o sea él ya tiene un precio político o sea la persona que hizo este lugar que va a ser un éxito, que va a explotar de chicos, eso es seguro" (Juan, entrevista personal, 29 de diciembre de 2009).

Sus palabras no estaban equivocadas, el funcionario en cuestión parecía estar ya imaginando ese momento: "nuestra función digamos ahora, va a ser lograr que se ejecute el proyecto tal cual fue el diseño original y después inaugurarlo" (Director de Juventud, entrevista personal, 23 de marzo de 2010). Sin dudas, los jóvenes plantean nuevas propuestas de gestión y acción que suelen diferenciarse de las formas tradicionales de concebir el ejercicio político (Reguillo, 2012). El camino aquí era ya de ejercer su ciudadanía plenamente. Las tablas de skate los habían llevado mucho más lejos de lo que ellos podrían haber imaginado.

\section{Triunfo en los votos y apogeo del proyecto 115}


En la votación del presupuesto participativo 2010 de la Municipalidad de La Plata, llevada adelante en diciembre 2009, participaron 44983 ciudadanos platenses y fueron presentados 370 proyectos. Entre los 45 proyectos que resultaron ganadores a través del voto estaba el 115: los skaters tenían esta vez un logro entre sus manos. Los jóvenes skaters manifestaban su alegría, pero a su vez el descontento con algunos manejos que consideraban extraños, entendiendo que la votación no había sido legal y evidenciando un cierto desagrado por manejos de la política tradicional, que veían y consideraban poco éticos. Asimismo, el resultado de la votación se mezclaba con un cierto escepticismo respecto a la concreción de la obra a futuro, ya que hacía un tiempo que venían escuchando promesas referidas a los proyectos de skatepark. Las esperanzas de ver realizado el sueño del sitio propio para su práctica queda sintetizada en frases como la siguiente: "ahora vamos a ver qué pasa con esto y yo hasta que no tenga el skatepark no estoy contento" (Juan, entrevista personal, 29 de diciembre de 2009), o cuando afirmaban "Yo espero que se pueda hacer un skatepark como la gente, que esté bien diseñado todo y que realmente se haga en el tiempo que pusieron" (Marina, entrevista personal, 15 de enero de 2010). Unos meses después de la votación, en el foro de la web "Skatepark público en La Plata", uno de los participantes expresaba su descontento con la demora: "No están haciendo nada!!! A reclamar! Fui a sacar fotos del lugar para demostrar que no están haciendo nada! Que no movieron ni un dedo todavía. Además así a la hora de reclamar no vamos con las manos vacías y nos boludean. Pero no es solo culpa de la municipalidad, sino, también de nosotros que no nos organizamos para movernos bien en conjunto y que salga adelante" (Foro web, 20 de marzo de 2010). Para esa misma época, el director de Juventud nos explicaba que lo que faltaría es "una vez que se termine el diseño, lograr la cesión definitiva del predio, y una vez lograda la cesión definitiva, realizar la construcción" (Director de Juventud, entrevista personal, 23 de marzo de 2010).

Pasaron ya varios años desde la votación del presupuesto participativo y aún la obra no se ha iniciado, así como no se la volvió a mencionar en los medios de comunicación. A la fecha de presentación de nuestra investigación, la municipalidad misma no había dado ninguna explicación pública de por qué el proyecto 115 no se concretó. Para los jóvenes la iniciativa parecería ya encaminada a un profundo olvido y consideran que no se hará nunca más. Una fuente oficial consultada informó que el proyecto 115 no fue descartado totalmente, pero el problema persiste dado que hasta ahora no se ha encontrado otro lugar en esa zona donde concretar el skatepark. En ese mismo momento, otras iniciativas referidas a espacios para la práctica del skate comenzaban a ver la luz.

\section{Nuevas pistas de skate para la ciudad}

En el transcurso del año 2011 son construidos tres skateparks en la ciudad. El primero en ser inaugurado fue el skatepark de calle 32 y 26, luego el del Camino General 
Belgrano y 514, y, finalmente, el tercero en Villa Elvira, ubicado en las calles 82 bis y 118. Los dos primeros fueron objeto de críticas antes y después de su finalización. Los skaters consideraban que no respondían a las medidas y formas correctas de un skatepark $\mathrm{y}$, además, opinaban que de la manera en que iban a ser construidos originalmente eran peligrosos. Pero la controversia no solo tenía ribetes técnicos, sino que también estaba ligada a la manera en que esos dos proyectos de pistas se habían generado: en el desarrollo de ninguno de los dos habían participado ni habían sido consultados los jóvenes. Solo se tuvo en cuenta su opinión luego de que las críticas aparecieron reflejadas en los medios de comunicación. En ambos skateparks se puso en evidencia una cuestión que ya había sido expresada por los jóvenes respecto al proyecto 115: la necesidad de convocar a un arquitecto especializado que conociera del tema. Los profesionales a cargo de la obra, que no tenían experiencia previa en diseños de pistas, se reunieron con algunos de los skaters que aparecieron reclamando en los diarios para tener en cuenta sus sugerencias. Esas modificaciones de último momento redujeron el grado de peligrosidad $y$, aunque no lograron que el lugar se transformara en una pista verdaderamente atractiva para todos los jóvenes, es de señalar que fueron tenidas en cuenta las opiniones de los skaters. Es criticable que esto haya sucedido a último momento a partir de las quejas, y no por un interés genuino de escuchar a los protagonistas. Está claro que una vez más la gestión pública estatal ya no podía ignorar a los jóvenes.

El tercer skatepark, localizado en el barrio de Villa Elvira, en el sector denominado Barrio Jardín, quizás fue el ejemplo más genuino del proceso de construcción colectiva, respetándose la elección popular del presupuesto participativo. ${ }^{15}$ Por un lado, se concretaba el deseo de la gente que lo votó y, por el otro, se incorporaba en su diseño, concepción y puesta en funcionamiento a un arquitecto especializado en pistas de skate. Esta idea había sido manifestada por los skaters a la municipalidad para ser tenida en cuenta tanto para el proyecto de Plaza Belgrano como para el Proyecto 115, pero en ninguna de esas dos ocasiones sus interlocutores habían considerado seriamente esa posibilidad.

Es necesario señalar, sin embargo, que no se llegó a la implementación de los skateparks existentes partiendo solamente de la iniciativa de una política pública municipal enfocada en crear espacios deportivos para jóvenes, sino por las propias acciones llevadas a cabo a lo largo de esos diez años por los skaters, y particularmente, por su esfuerzo reivindicatorio por devenir 'visibles' para el resto de los ciudadanos y de la ciudad. Habían transcurrido muchos años de lucha manifestando la necesidad de un espacio propio. Por otro lado, consideramos que la decisión municipal de construir los skateparks también respondía, de manera indirecta, a la oposición y a las presiones

\footnotetext{
${ }^{15}$ El skatepark de Villa Elvira también había sido uno de los ganadores del presupuesto participativo 2010, presentado con el número 367 y descripto como "Acondicionamiento de plaza de Barrio Jardín con pista de skate, luminarias, cordones para caminos y rampa para discapacitados en cada esquina".
} 
de los vecinos para que la práctica skater no se lleve adelante en las zonas céntricas. La intención de desalojarlos diplomáticamente de sus habituales sitios de práctica estaba explicita. ${ }^{16}$

La participación activa de jóvenes en pos de la construcción de un espacio propio no se ha evidenciado solo en La Plata, sino que se ha producido también en otras urbes. Acciones similares con participación juvenil de skaters han sido relevadas en diferentes países, por ejemplo en Italia (Fenoglio, 2004), en Suiza (Jaccoud y Malatesta, 2008), Estados Unidos (Pletsch, 2007), Brasil (Venini Falconi, 2008), e incluso en otras ciudades de Argentina (Reta, 2011). Desde nuestra perspectiva, consideramos que los jóvenes que practican skate están también participando en política desde un lugar novedoso, inaugurando nuevos lugares de participación política, de enunciación y de comunicación (Reguillo Cruz, 2000).

\section{A modo de conclusión: ciudadanía y skate}

Hemos intentado analizar dos cuestiones que se dieron casi simultáneamente y que consideramos estuvieron estrechamente entrelazadas: los sucesos acaecidos en relación con la práctica skater en el Teatro Argentino -conflictos, negociaciones, acuerdos-, y las acciones de los skaters en pos de un skatepark, incluyendo la intervención en el presupuesto participativo 2010 con el proyecto 115. Asimismo, hemos hecho mención a notas presentadas previamente en el Concejo Deliberante (2001 y 2008) que consideramos jalonaron el camino de las acciones en pos del reconocimiento de la práctica de skate en la ciudad. Hemos también considerado la implementación reciente de tres skateparks en la ciudad y cómo se relaciona con un proceso iniciado con anterioridad por los jóvenes.

Creemos que en estas manifestaciones que hemos intentado relatar y explicar, subyace la búsqueda de espacios de parte de estos jóvenes en la vida social, que se constituye en una manera de construir ciudadanía. Entendemos, siguiendo a Jelin, que

...tanto la ciudadanía como los derechos están siempre en proceso de construcción y cambio. Esto implica alertar sobre el peligro de identificar la ciudadanía con un conjunto de prácticas concretas -sea votar en elecciones o gozar de la libertad de expresión, recibir beneficios sociales del Estado o cualquier otra práctica específica. Si bien estas prácticas constituyen el eje de las luchas por la ampliación de los derechos en situaciones históricas determinadas, desde una perspectiva analítica el concepto de ciudadanía hace referencia a una "práctica conflictiva vinculada al poder, que refleja las luchas acerca de quiénes podrán decir qué en el proceso de definir cuáles son los

\footnotetext{
16 Los medios locales reproducían las declaraciones de un funcionario municipal al respecto: "Los deportistas podrán focalizarse únicamente en estos espacios, abandonando así los actuales centros de reunión, como el Teatro Argentino, o las escaleras de la Torre 1" (Diario El Día, 20/12/2010; la cursiva es nuestra).
} 
problemas sociales comunes y cómo serán abordados" (Van Gunsteren, 1978) (Jelin, 1997: 194).

Los skaters buscan un lugar en la sociedad y en la ciudad. A través de la visibilización como estrategia política, intentan hacer que sus prácticas sean aceptadas y valoradas. En palabras de Reguillo Cruz: "Las culturas juveniles se vuelven visibles. Los jóvenes, organizados o no, se convierten en 'termómetro' para medir los tamaños de la exclusión, la brecha creciente entre los que caben y los que no caben, es decir, 'los inviables', los que no pueden acceder a este modelo y que por lo tanto no alcanzan el estatuto ciudadano" (Reguillo, 2000: 148). El especialista en skate Ian Borden completa ese pensamiento afirmando "los skaters se insertan en un largo proceso en la historia de la ciudad, de la lucha de los sin poder y de los marginados por un espacio social propio" (Borden, 2002: 75; la traducción es nuestra). Sin lugar a dudas los hechos relatados han contribuido a la mayor visibilidad de quienes lo practican.

Los jóvenes intentan desarrollarse a través del vínculo con otros, buscando interlocutores, de la misma manera que todas las personas necesitamos de los otros para vivir en sociedad. En este caso, los skaters, además de sus propios pares, encontraron 'esos otros' en varios adultos (tales como el presidente de la asociación que los apoyó en la nota por un espacio propio, el director de Juventud, el director del Teatro Argentino, el presidente de la Junta Comunal). Encuentros que generaron debates, peleas y disensos, pero también acuerdos centrados en el diálogo. Estaban generando una construcción colectiva y habían encontrado partenaires para ello. Construían un 'nosotros' que se reflejaba claramente en los 'otros'. Quizás el objetivo era dejar de ser un nosotros aislado de esos otros, para comenzar a conformar un nosotros realmente sentido como un 'todos' en la ciudad.

Las acciones llevadas adelante por los skaters de La Plata, tales como la decisión de continuar con el proyecto de skatepark de Plaza Belgrano llevándolo al proyecto participativo, el hecho de unirse y consolidar el proyecto 115 , la participación en las asambleas, la campaña en pro de la votación de su proyecto, así como las negociaciones y acuerdos con el director del Teatro Argentino, podrían inscribirse dentro de lo que Reguillo (2012) propone llamar

...las estrategias de la micropolítica, aquella que transcurre en el día a día, a espaldas de las instituciones ciegas y sordas, en el pequeño evento en que un "yo firmo", "yo marcho", "yo canto", "yo digo" confiere a la agencia juvenil su potencia de cambio (2012: 15, la cursiva es nuestra).

Indudablemente, las definiciones y decisiones asociadas a la construcción de espacios públicos destinados a las prácticas lúdico-deportivas y de esparcimiento son hechos políticos y/o con significación política. Toda la disputa y el proceso por lograr la 
construcción de un skatepark encierra una necesaria definición de qué es lo legitimo en la ciudad y de quién puede definir y cómo esa legitimidad.

Los jóvenes entrevistados en la investigación (Saraví, 2012) evidenciaban una cierta tristeza o desazón frente a hechos que no se concretaban de la manera que ellos esperaban. El ejemplo más claro fue el no poder respetar los acuerdos establecidos en el teatro. También hemos encontrado esas sensaciones cuando se manifestaban en relación con la construcción de dos pistas que no respondían a sus necesidades, así como frente a la no concreción del proyecto 115. Sin embargo, todos esos hechos con resultados en apariencia amargos, fueron jalones que marcaron y marcan un camino hacia un reconocimiento y aceptación del skate en la ciudad de La Plata. Pasos necesarios de un proceso en el cual los jóvenes buscaron obtener una carta de ciudadanía plena para su práctica y para sí mismos.

\section{Bibliografía}

Almada Flores, Héctor Arón. (2010). El Skateboarding en Tijuana y Monterrey. La lealtad, las reglas y los significados en la construcción de las identidades de los deportistas. Tesis de Maestría en Estudios Socioculturales, El Colegio de la Frontera Norte, México.

Borden, Ian. (2002). Skaterboading e superficie urbane. Ottagono, No 152, pp. 70 - 75.

Brandão, Leonardo. (2006). Corpos deslizantes, corpos desviantes: a prática do skate e suas representações no espaço urbano (1972-1989). Tesis de Maestría en Historia, Universidade Federal da Grande Dourados (UFGD).

Calogirou, Claire y Touché, Marc. (1995). Sport-passion dans la ville : le skateboard. En Terrain, Numéro 25, Des sports (septembre). Recuperado el 15 de Julio de 2013 de http://terrain.revues.org/document2843.html

Calogirou, Claire y Touché, Marc. (2000). Le skateboard, une pratique urbaine, ludique et de liberté. Hommes et Migrations, n²1226, Au miroir du sport, pp. 33 - 43.

Camino, Xavi. (2008). Reinterpretando la ciudad: la cultura skater y las calles de Barcelona. Apunts Educación Física y deportes, número 91, 1er trimestre, pp. 54 65.

Carrión, Fernando. (2007). Espacio público: punto de partida para la alteridad. En Segovia, Olga (edit.) Espacios públicos y construcción social. Hacia un ejercicio de ciudadanía. Santiago de Chile: Ediciones SUR.

Chaves, Mariana (2010). Jóvenes, territorios y complicidades. Una antropología de la juventud urbana. Buenos Aires: Espacio Editorial.

Cornejo Améstica, Miguel; Villalobos Clavería, Alejandro; Cerda Etchepare, Gamal; Cuadra Montoya, Liliana. (2006). El skate urbano juvenil: una práctica social y corporal en tiempos de la resignificación de la identidad juvenil chilena. Revista Brasileira de Ciencias do Esporte, Campinas, volumen 28, número 1, setiembre, pp. $39-53$. 
De Certeau, Michel. (1996). La invención de lo cotidiano I. Artes de hacer. México: Universidad Iberoamericana e ITESO.

Failache, Florencia; Olivera, Juan. (2002). Skaters: saltando obtáculos urbanos. En Filardo, Verónica (Coord.) Tribus urbanas en Montevideo. Nuevas formas de sociabilidad juvenil. Montevideo: Ediciones Trilce.

Fenoglio, Cristina. (2004). Skatepark occasione di partecipazione. Actas del VIII Congreso Internacional de Ciudades Educadoras. Recuperado el 10 de diciembre de 2014 en http://www.bcn.cat/oidp/9conferencia/it/skatepark.swf

Genro, Tarso y De Souza, Ubiratan. (1998). Presupuesto participativo: la experiencia de Porto Alegre. Buenos Aires: Editorial Eudeba.

Graeff Bastos, Billy. (2006). Estilo de vida e trajetórias sociais de skatistas: da vizinhança ao fazer o corre. Tesis de Mestrado em Ciências do Movimento Humano, Escola de Educação Física, UFRGS.

Honorato, Tony. (2005). A tribo skatista e a instituição escolar: o poder escolar em uma perspectiva sociológica. Tesis de Maestría en Educación, Programa de PósGraduação em Educação, Faculdade de Ciências Humanas, Universidade Metodista de Piracicaba (Unimep). Piracicaba, SP.

Jaccoud, Christophe y Malatesta, Dominique. (2008). Nouvelles pratiques sportives. Une citoyenneté contemporaine. Terra cognita, Número especial Sport, mayo, pp. 16 19.

Jelin, Elizabeth. (1997). Igualdad y Diferencia: Dilemas de la Ciudadanía de las Mujeres en América Latina. Ágora. Cuadernos de estudios políticos. Año 3, N07, pp. 189 2014.

Lindón, Alicia. (2007). La ciudad y la vida urbana a través de los imaginarios urbanos. Eure, revista Latinoamericana de Estudios Urbano-Regionales, volumen XXXIII, número 99. Santiago de Chile, agosto. Recuperado el 1 de marzo de 2015 en http://www.scielo.cl/pdf/eure/v33n99/art02.pdf

Otaviani, Eduardo. (2009). El espacio público, sostén de las relaciones sociales. Cuadernos del Centro de Estudios en Diseño y Comunicación, Facultad de Diseño y Comunicación, Universidad de Palermo. Año 10, Número 30, noviembre, pp. 181 189.

Pagani, María Laura. (2008). El gobierno local como promotor de políticas de participación ciudadana. Aprendizajes y dificultades en dos experiencias municipales. Cuestiones de Sociología, No 4, pp. 78-101. Departamento de Sociología, Facultad de Humanidades y Ciencias de la Educación, UNLP.

Pegard, Olivier. (1996). Ethnographie d'une pratique ludique urbaine : le skateboard sur la place Vauquelin à Montréal. Tesis de Doctorado, Université de Montréal.

Pletsch, Michelle. (2007). Montando en monopatín en Tacoma. Documento de trabajo para la Conferencia sobre Inclusión Social y Políticas Innovadoras. Publicación del Observatorio Ciudades Inclusivas, Comisión de Inclusión Social, Democracia 
Participativa y Derechos Humanos de Ciudades y Gobiernos Locales Unidos (CGLU).

Reguillo Cruz, Rossana. (2000). Emergencia de culturas juveniles. Estrategias del desencanto. Bogotá: Grupo Editorial Norma.

Reguillo Cruz, Rossana. (2012). Culturas juveniles: Formas políticas del desencanto (Introducción). Buenos Aires: Siglo XXI Editores.

Reta, María. (2011). Ciudad: entre la negación del tejido urbano y su construcción. Un caso en la Patagonia Norte Argentina. Actas del XXVIII Congreso Internacional de la Asociación Latinoamericana de Sociología (ALAS). 6 al 11 de Septiembre, UFPE, Recife.

Saraví, Jorge Ricardo; Chaves, Mariana; Machemehl, Charly. (2012). Logiques d'appropriation et politiques de l'espace urbain: jeunes skateurs dans la ville de La Plata en Argentine. Loisir et société, volumen 34, n²1, printemps, pp. 121 - 148.

Saraví, Jorge Ricardo. (2012). Skate, espacios urbanos y jóvenes en la ciudad de La Plata. Tesis de Maestría en Educación Corporal. Facultad de Humanidades y Ciencias de la Educación, UNLP. Recuperado el 25 de septiembre de 2014 en http://sedici.unlp.edu.ar/handle/10915/31293

Segura, Ramiro. (2010). Representar. Habitar. Transitar. Una antropología de la experiencia urbana en la ciudad de La Plata. Tesis de Doctorado en Ciencias Sociales. Universidad Nacional de General Sarmiento (UNGS), Instituto de Desarrollo Económico y Social (IDES).

Uvinha, Ricardo. (1997). Lazer na adolescência: uma análise sobre os skatistas do $A B C$ paulista. Tesis de Maestría, Departamento de Estudos do Lazer da Faculdade de Educação Física, Universidade Estadual de Campinas.

Venini Falconi, Andrea. (2008). Lazer no parque da cidade: espaço urbano, sociabilidade e consumo em Sobral /CE. Monografia apresentada como requisito para a obtenção de título de Bacharel em Ciências Sociais. Universidade Estadual Vale do Acaraú (UEVA). 